\title{
Influence of the Processing Temperature on the Microstructure, Texture, and Hardness of the 7075 Aluminum Alloy Fabricated by Accumulative Roll Bonding
}

\author{
P. HIDALGO, C.M. CEPEDA-JIMÉNEZ, O.A. RUANO, and F. CARREÑO
}

\begin{abstract}
The 7075 alloy is an Al- $\mathrm{Zn}-\mathrm{Mg}-\mathrm{Cu}$ wrought age-hardenable aluminum alloy widely used in the aeronautical industry. The alloy was accumulative roll bonded at $300{ }^{\circ} \mathrm{C}(573 \mathrm{~K}), 350{ }^{\circ} \mathrm{C}$ $(623 \mathrm{~K})$, and $400{ }^{\circ} \mathrm{C}(673 \mathrm{~K})$, and the microstructure, texture, and hardness were investigated. $\mathrm{Cell} /(\mathrm{sub})$ grain size in the nanostructured range, typical $\beta$-fiber rolling texture, and homogeneous hardness through thickness were determined in all cases. Misorientation was different at each processing temperature. At $400{ }^{\circ} \mathrm{C}$, the presence of elements in solid solution and the partial dissolution of the hardening precipitates lead to a poorly misoriented microstructure with a high dislocation density and a homogeneous $\beta$-fiber texture of low intensity, typical of intermediate degrees of rolling. At $350{ }^{\circ} \mathrm{C}$ and $300{ }^{\circ} \mathrm{C}$, highly misoriented microstructures with smaller dislocation density and intense heterogeneous $\beta$-fiber rolling texture are observed, especially at $350{ }^{\circ} \mathrm{C}$, wherein the degree of dynamic recovery (DRV) is higher. Hardness of the accumulative roll bonded samples is smaller than that of the starting material due to particle coarsening, and it is affected by solid solution and/or by fine precipitates produced by reprecipitation of the elements in solid solution.
\end{abstract}

DOI: $10.1007 / \mathrm{s} 11661-009-0138-1$

(C) The Minerals, Metals \& Materials Society and ASM International 2010

\section{INTRODUCTION}

SEVERE plastic deformation (SPD) is one of the most effective ways to produce ultrafine-grained (UFG) materials, with a mean grain size smaller than $1 \mu \mathrm{m}$, in bulk macroscopic materials. ${ }^{[1,2]}$ Ultrafine-grained materials are expected to perform prominent mechanical properties. Accumulative roll bonding (ARB), originally developed by Saito et al.,${ }^{[3]}$ is one of the most popular SPD techniques. ${ }^{[4-6]}$ Accumulative roll bonding does not require any special equipment and enables the production of UFG structures in bulk sheet materials. Moreover, continuous rolling mills can be readily used in industry for ARB. For these reasons, ARB is perhaps the most promising SPD process for industrial practice.

The ARB process consists of cutting sheets into stacks and roll bonding. By repeating this procedure, very high strains can be introduced into the material. As a result, significant structural refinement can be achieved. ${ }^{[7]}$ It has been verified that the redundant shear strain that may be introduced to the material significantly contributes to grain refinement. ${ }^{[8,9]}$ To date, the ARB process has been performed mostly by two layers stacking and rolling by 50 pet reduction in thickness. If the number of stacking layers and the reduction per pass increase, some advantages will be expected: ${ }^{[10,11]}$ (1) the productivity

P. HIDAlGO, Ph.D. Student, C.M. CEPEDA-JIMÉNEZ, Postdoctoral Researcher, O.A. RUANO, Professor, and F. CARREÑO, Staff Researcher, are with the Department of Physical Metallurgy, CENIM, CSIC, 28040 Madrid, Spain. Contact e-mail: hidalgo@cenim. csic.es

Manuscript submitted August 21, 2009.

Article published online January 22, 2010 would increase, (2) the bonding strength between the stacked layers would improve, and (3) more severe compressive and shear deformation could be introduced into the materials.

The UFG metals produced by high strain deformation are generally characterized by a mixture of highangle boundaries (HABs) and low-angle boundaries (LABs). Furthermore, the presence of a density of interior dislocations within the volumes between the boundaries is also a common feature. ${ }^{[12]}$ These characteristics strongly depend on the metal and some of the processing conditions applied, such as temperature. Additionally, similar textures to those obtained by conventional rolling are generated by ARB. ${ }^{[13,14]}$

In the present investigation, a 3:1 reduction per pass ARB process was applied to the commercial 7075 aluminum alloy at three different temperatures for which a good bonding is achieved $\left(300{ }^{\circ} \mathrm{C}, 350{ }^{\circ} \mathrm{C}\right.$, and $400{ }^{\circ} \mathrm{C}$ ). This alloy is one of the strongest wrought aluminum alloys, and as such, it is widely used for the construction of plane structures such as wings and fuselages because of its excellent strength/weight rate. ${ }^{[15]}$ Application of the ARB process to the 7075 aluminum alloy would result in an improvement of the superplastic properties and thereby in important savings in the aeronautical industry. However, since this alloy is age hardenable, it contains thermally unstable precipitates that may constitute an obstacle to grain refinement and misorientation increment and, therefore, may affect microstructure, texture, and mechanical properties. The aim of the present study is to clarify the effect of the processing temperature on the final microstructure, texture, and hardness of the 7075 aluminum alloy 
severely deformed by ARB in order to find the optimum processing parameters.

\section{MATERIAL AND EXPERIMENTAL PROCEDURE}

The material used for this study was the as-received commercial $7075 \mathrm{Al}$ alloy sheet in the T6 condition. The chemical composition of the alloy is shown in Table I. Optical observation revealed a fully-recrystallized microstructure with mean grain thickness, width, and length of $4.2,47.2$, and $59.6 \mu \mathrm{m}$, respectively. The texture of the alloy contained a mixture of near cube orientations with those along a [001] fiber aligned with the equivalent rolling direction. The alloy sheet had a thickness of $2 \mathrm{~mm}$ and it was divided into pieces of dimensions $2 \times 30 \times 180 \mathrm{~mm}^{3}$. Initially, two pieces were fastened by steel wires. The two-layer 4 -mm-thick stack was held for 5 minutes at the processing temperature $\left(300{ }^{\circ} \mathrm{C}, 350{ }^{\circ} \mathrm{C}\right.$, and $\left.400{ }^{\circ} \mathrm{C}\right)$ in a preheated electric furnace and then deformed to $1.33-\mathrm{mm}$-thick sheet by a 3:1 rolling pass using a two-high mill with a roll diameter of $131 \mathrm{~mm}$ and a peripheral roll speed of $346 \mathrm{~mm} / \mathrm{s}$ in nonlubricated conditions without changing the rolling direction. Immediately after rolling, the specimen was quenched in water at room temperature. Afterwards, the rolled specimen was cut into three pieces of the same length and then supplied to the next 3:1 hot rolling pass. This last step was repeated once more. In this way, each specimen experienced three 3:1 hot rolling

Table I. Chemical Composition of the 7075 Al Alloy Studied (Mass Percent)

\begin{tabular}{lcccccccc}
\hline $\mathrm{Si}$ & $\mathrm{Mg}$ & $\mathrm{Fe}$ & $\mathrm{Zn}$ & $\mathrm{Cu}$ & $\mathrm{Ti}$ & $\mathrm{Cr}$ & $\mathrm{Mn}$ & $\mathrm{Al}$ \\
\hline 0.052 & 2.51 & 0.19 & 5.68 & 1.59 & 0.025 & 0.19 & 0.007 & bal \\
\hline
\end{tabular}

passes, after which the method produced an approximately $1.33-\mathrm{mm}$-thick sheet containing 18 layers. The schematic illustration of the ARB process undergone in the present investigation is shown in Figure 1. As can be seen in the figure, before each stacking pass, the pieces were degreased with methyl ethyl ketone, and after each rolling pass, the roll-bonded specimen was immediately water cooled. The processing temperatures were selected between the minimum temperature that produces bonding and the solutionization temperature of the alloy. The three accumulative roll bonded samples are listed in Table II, together with their processing temperature and total true rolling strain. In this analysis, true strain was calculated as $\varepsilon=-\ln \left(h_{0} / h\right)$, where $h_{0}$ and $h$ are the initial and the final thickness of the rolled specimen, respectively.

Due to the fine scale, the microstructures of the accumulative roll bonded samples were investigated by transmission electron microscopy (TEM). The TEM studies were conducted with a JEOL* JEM 2000 FX II

*JEOL is a trademark of Japan Electron Optics Ltd., Tokyo.

microscope operated at $200 \mathrm{kV}$. Thin disk-shaped foils were prepared by twin-jet polishing for TEM observation. The electropolishing was carried out in a $300 \mathrm{~mL}$ $\mathrm{HNO}_{3}+700 \mathrm{~mL} \mathrm{CH} \mathrm{CH}_{3} \mathrm{OH}$ solution at $-25^{\circ} \mathrm{C}$ and $15 \mathrm{~V}$.

Table II. Processing Temperature and Total True Strain of the Accumulative Roll-Bonded Samples

\begin{tabular}{lcc}
\hline Sample & Processing Temperature $/{ }^{\circ} \mathrm{C}$ & Total Strain \\
\hline 30DT3 & 300 & 3.25 \\
35DT3 & 350 & 3.24 \\
40DT3 & 400 & 3.25 \\
\hline
\end{tabular}

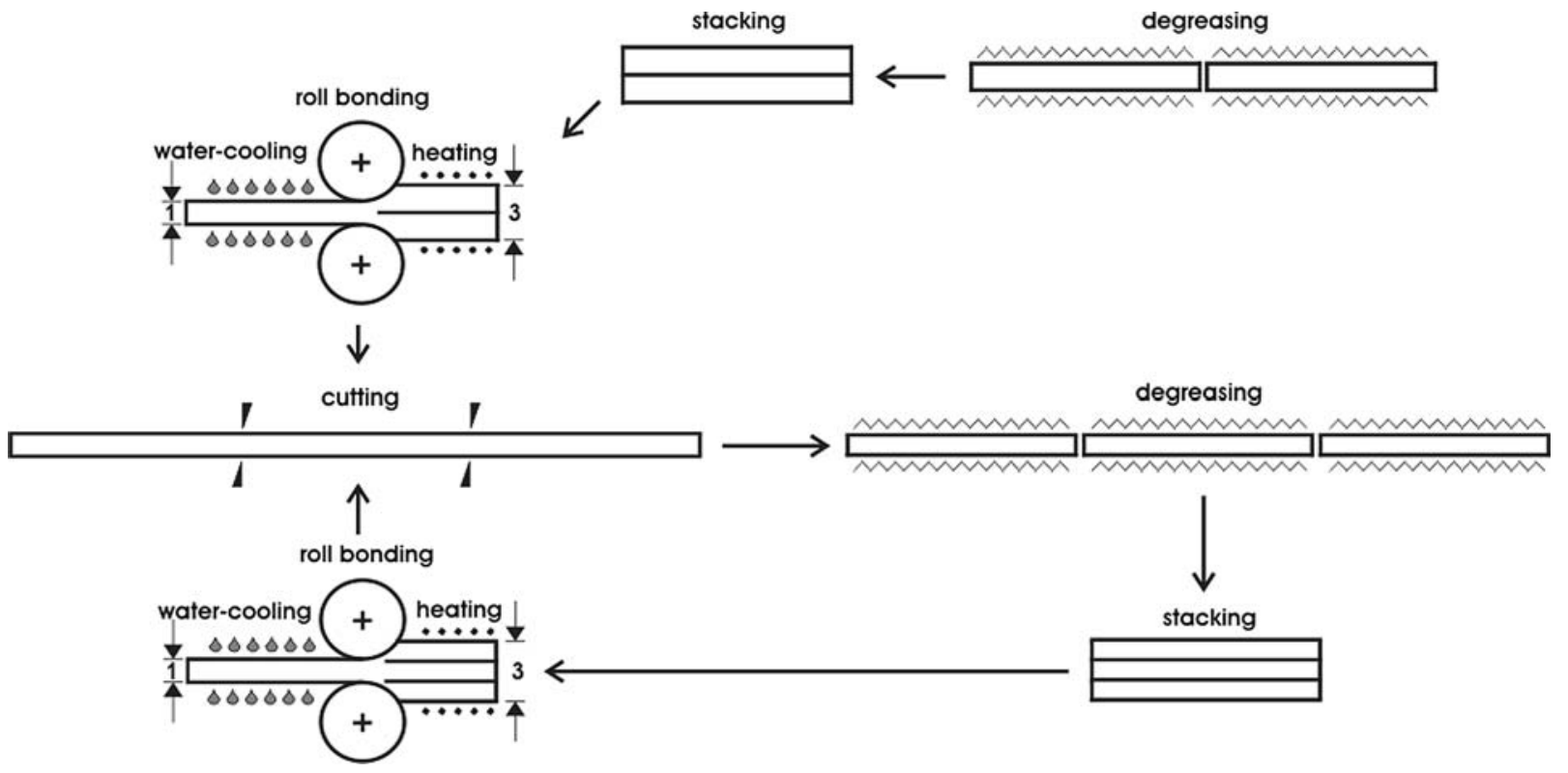

Fig. 1-Schematic illustration showing the ARB process carried out in the present investigation. 
Electron backscatter diffraction (EBSD) measurements were carried out to characterize microstructural and crystallographic features. The EBSD mapping was conducted using the acquisition package of the Oxford Channel 5 software in a JEOL JSM $6500 \mathrm{~F}$ scanning electron microscope (SEM) equipped with a fieldemission gun operated at $20 \mathrm{kV}$ and a working distance of $15 \mathrm{~mm}$. The EBSD data were subsequently analyzed by the same software. Boundary misorientations below $2 \mathrm{deg}$ were not taken into account to remove the orientation noise produced due to the limited angular resolution of the EBSD technique. Boundaries with misorientations between 2 and $15 \mathrm{deg}$ were defined as LABs and those with misorientation $>15 \mathrm{deg}$ as HABs. The EBSD samples were electropolished in the preceding solution at $-15^{\circ} \mathrm{C}$ and $15 \mathrm{~V}$. The same specimens were used to examine the alloy precipitates, and samples etched with Keller's reagent were used to examine the bonding quality. These examinations were performed in the SEM described previously.

A Siemens D500 (Munich, Germany) diffractometer was used to investigate the macrotexture of the accumulative roll bonded samples by means of the Schulz reflection method. The X-ray radiation used was $\mathrm{Cu} K_{\alpha}$. The $\{111\},\{200\},\{220\}$, and $\{311\}$ pole figures were reconstructed from the orientation distribution functions (ODFs) assuming orthogonal sample symmetry using the TexEval MFCApplication software (Bruke AXS, Billerica, MA). Texture was measured on a flat surface prepared by mechanical grinding and polishing.

Vickers microhardness tests were performed at room temperature using a Matsuzawa Seiki MHT-1 machine (Tokyo, Japan) with a square pyramidal indenter and a load of $10 \mathrm{~g}$ for 15 seconds. Indentation tests were made along the ND direction covering the entire thickness. It was important to keep a distance of about 3 times the average diameter of indentation between successive indentations in order to avoid their deformation zones to interfere each other and therefore to obtain anomalous results. The specimens for hardness evaluations were mounted and then ground and polished.

Samples parallel to the rolling plane were used for TEM, EBSD, and SEM precipitate examinations and texture analysis, while samples parallel to the longitudinal-transverse section were used for SEM bonding examinations and indentation tests. In the case of rolling plane measurements, the examined areas were located near the center of the thickness at about the layer indicated by the gray spot in Figure 2.

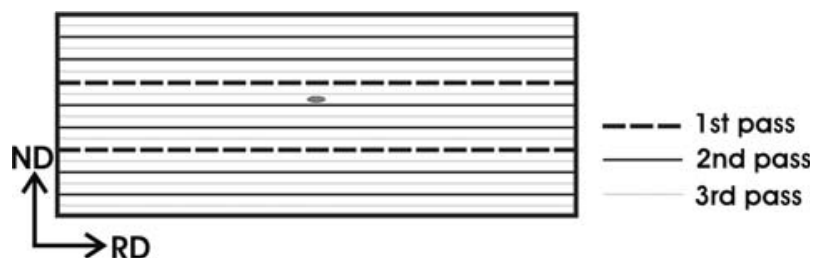

Fig. 2-Schematic diagram showing the area used for TEM, EBSD, and SEM precipitate examinations and texture analysis (about 40 pct in depth from the surface).

\section{RESULTS}

Three accumulative roll bonded samples were successfully processed at $300{ }^{\circ} \mathrm{C}, 350{ }^{\circ} \mathrm{C}$, and $400{ }^{\circ} \mathrm{C}$ (named 30DT3, 35DT3, and 40DT3, respectively), in which good bonding between layers was achieved. The three samples suffered edge cracking from the second pass. However, this phenomenon was more pronounced in the samples processed at $300{ }^{\circ} \mathrm{C}$ and $400{ }^{\circ} \mathrm{C}$ than in that processed at $350{ }^{\circ} \mathrm{C}$.

Figures 3(a) through (c) show SEM micrographs of the accumulative roll bonded samples from the surface to the center. In the 30DT3 and 35DT3 samples, the interfaces introduced at each rolling pass are observed, while in the 40DT3 sample, they are observed occasionally, indicating that the bonding of the interfaces is better. Inclusions, presumably of alumina, and pittings caused by the etching, are seen. The oxides at interfaces are discontinuous, indicating that the surface oxide layers were disrupted during rolling, which allowed the material to flow within the oxide debris to produce bonding between the pieces to join. In the 30DT3 and 35DT3 samples, grain boundaries are not observed. However, in the 40DT3 sample, large grain boundaries parallel to the rolling direction are apparent.

Precipitates present in the as-received alloy are shown in Figure 4(a). On a macroscale, the particles were uniformly distributed. After ARB processing, precipitates tend to become larger due to coarsening during the heating steps. As can be seen in Figures 4(b) through (d), larger precipitates and interparticle distance are obtained with increasing processing temperature. In the same way, the amount of elements in solid solution is expected to increase with temperature. ${ }^{[16]}$

Figures 5(a) through (c) show TEM microstructures on the rolling plane of the accumulative roll bonded samples. Equiaxed cells/(sub)grains less than $1 \mu \mathrm{m}$ in diameter are seen. It has been observed that the grain shapes in severely ARB processed materials, ${ }^{[17]}$ as in conventional rolling, ${ }^{[18]}$ are lamellar or elongated when observed from TD and relatively equiaxed when observed from ND. That is, the ultrafine grains developed by the ARB have a pancake shape. The 30DT3 sample shows relatively clear boundaries and some dislocations within. In the 35DT3 sample, dislocation density is smaller and (sub)grains are limited by clearer boundaries, occasionally showing typical fringe contrast. Finally, the 40DT3 sample shows cell structures with quite high dislocation density in the cell interiors.

Mean boundary spacing along RD $\left(d_{l}\right)$ and mean boundary spacing along TD $\left(d_{w}\right)$ were quantitatively determined from the TEM micrographs as mean linear intercepts. Three different micrographs were employed for each accumulative roll bonded sample. The values of $d_{l}$ and $d_{w}$ are shown in Table III, together with the corresponding aspect ratios $\left(A R=d_{l} / d_{w}\right)$. The three accumulative roll bonded samples are constituted by very equiaxed cells/(sub)grains $(A R=1.01$ to 1.02$)$ in the nanostructured range $(<500 \mathrm{~nm})$. Unexpectedly, the three accumulative roll bonded samples have very similar (sub)grain sizes. 
(a)

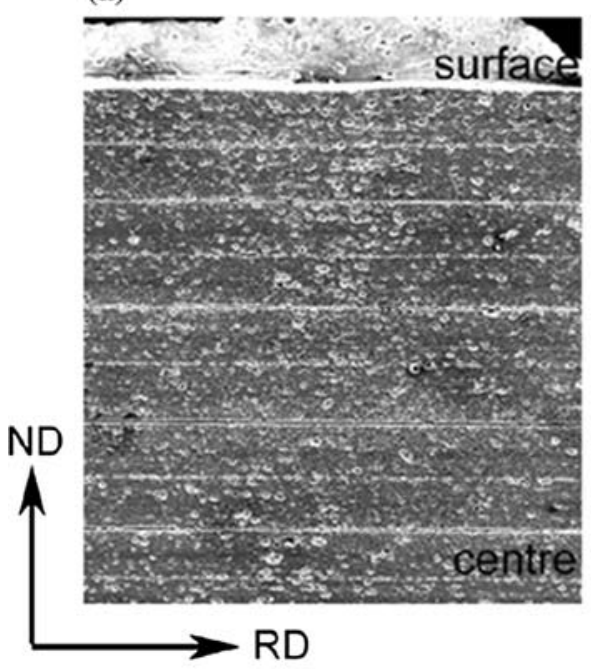

(b)

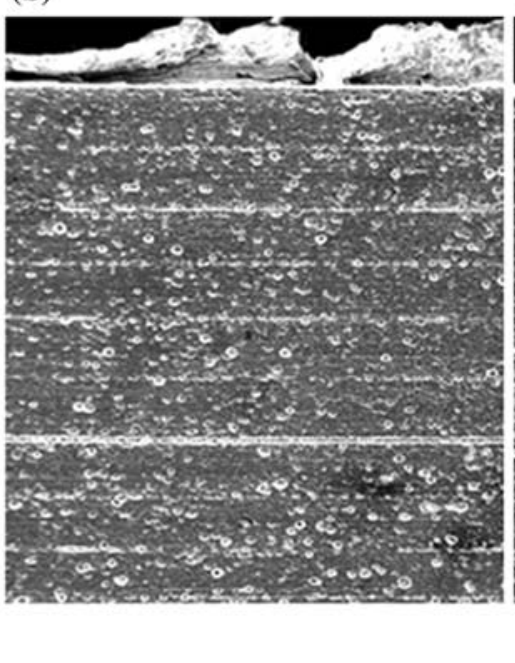

(c)

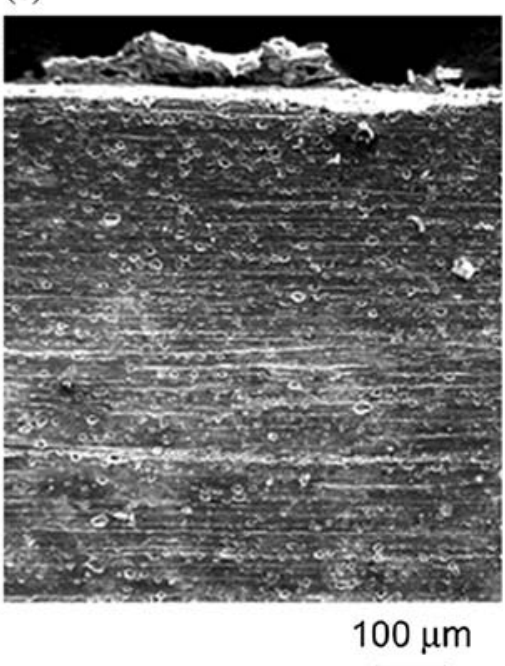

Fig. 3-SEM micrographs on the longitudinal-transverse section of the accumulative roll bonded samples: (a) 30DT3, (b) 35DT3, and (c) 40DT3.
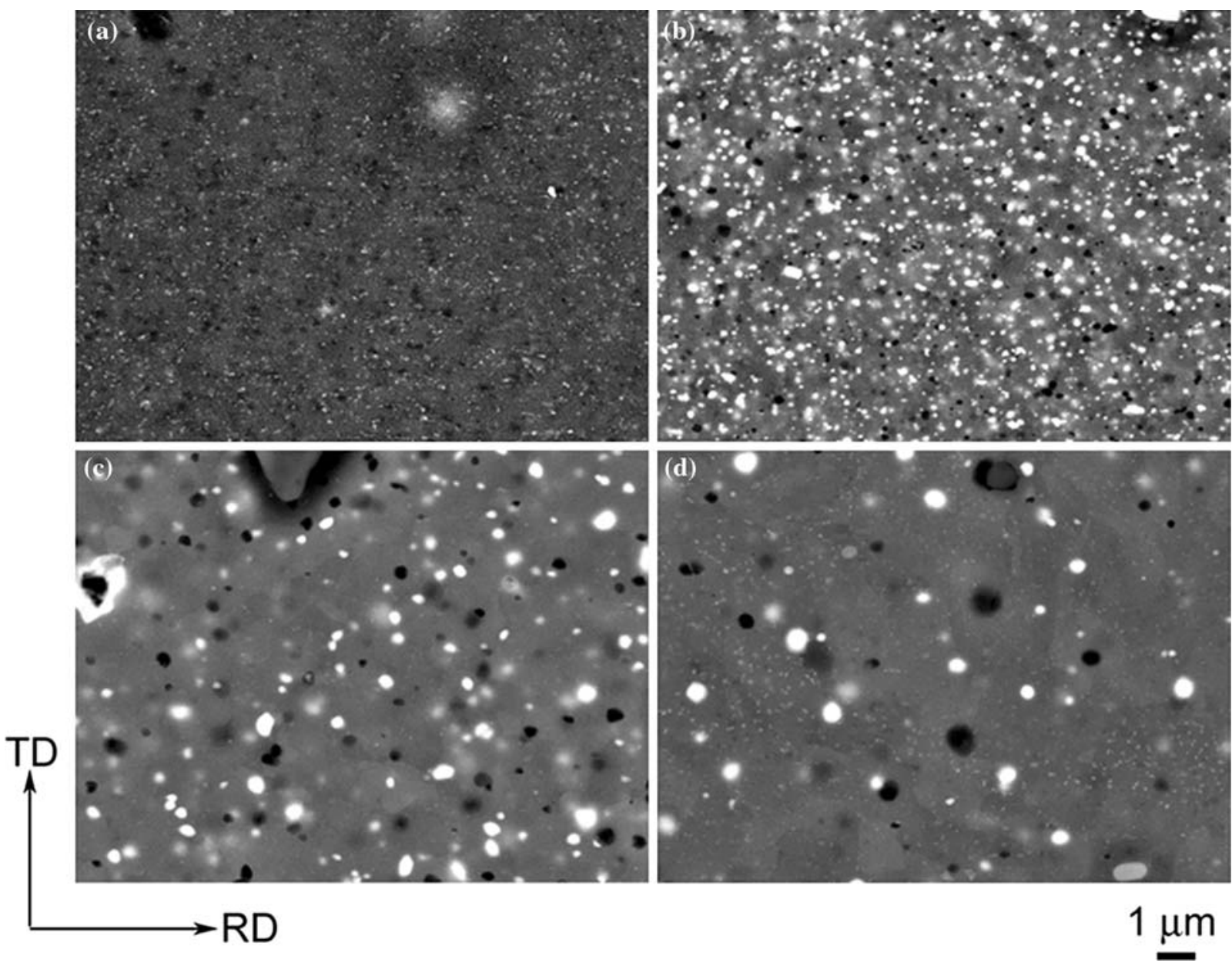

Fig. 4 Comparative SEM images showing the second-phase particles: (a) as-received, (b) 30DT3, (c) 35DT3, and (d) 40DT3.

From the EBSD measurements, orientation maps of the accumulative roll bonded samples were constructed, as shown in Figures 6(a) through (c). The EBSD measurements were performed at a step size of $0.26 \mu \mathrm{m}$. The LABs are depicted as gray lines, and the HABs as black lines. The colors in the maps represent 

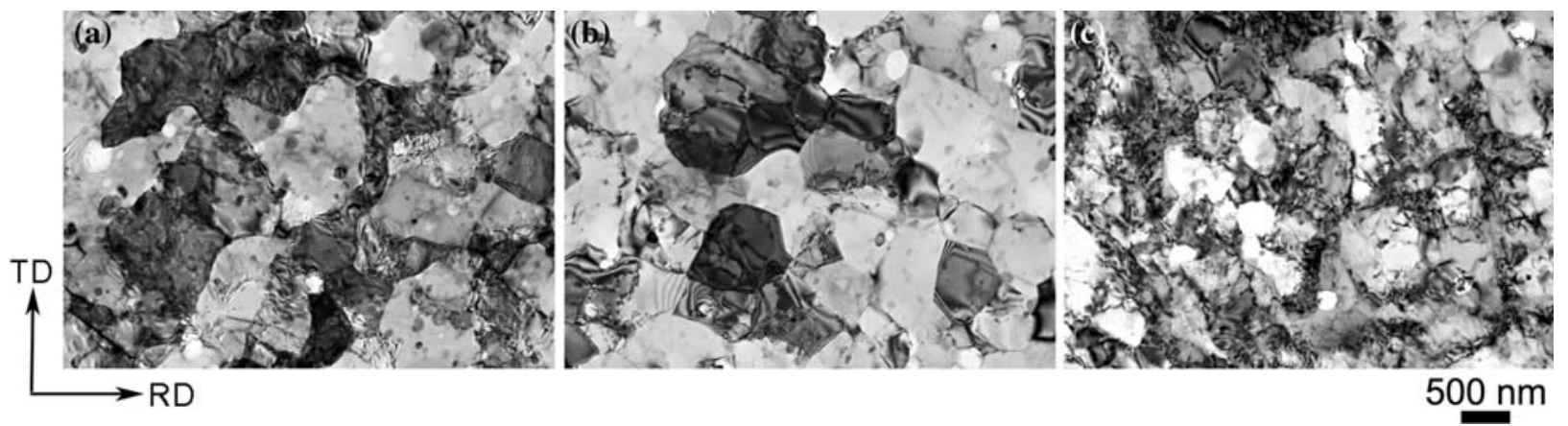

Fig. 5-TEM microstructures on the rolling plane of the accumulative roll bonded samples: (a) 30DT3, (b) 35DT3, and (c) 40DT3.

Table III. Microstructural Parameters of the Accumulative Roll Bonded Samples Determined from the TEM Micrographs on the Rolling Plane

\begin{tabular}{lccc}
\hline Sample & $d_{l} / \mathrm{nm}$ & $d_{w} / \mathrm{nm}$ & $A R$ \\
\hline 30DT3 & $430 \pm 77$ & $420 \pm 72$ & 1.02 \\
35DT3 & $449 \pm 81$ & $446 \pm 90$ & 1.01 \\
40DT3 & $449 \pm 66$ & $439 \pm 72$ & 1.02 \\
\hline
\end{tabular}

the crystallographic orientations parallel to the normal direction (ND). The correspondence between the colors and the crystallographic orientations is indicated in the stereographic triangle. The morphology of the (sub)grains observed is quite equiaxed in the three cases. There is a clear dominance of green, pink, and blue colors, typical of rolling texture, comprising $\alpha$ and/or $\beta$ fibers. In the 35DT3 sample, the rolling texture components are randomly distributed, while in the 30DT3 and the 40DT3 samples, they are not, especially in the $40 \mathrm{DT} 3$ one. In the 30DT3 and the 35DT3 samples, the microstructure is dominated by (sub)grains separated by LABs and HABs. However, it should be noted that the density of HABs is higher in the 35DT3 sample than in the 30DT3 one. Concerning the 40DT3 sample, a small level of grain subdivision and a small fraction of HABs are observed.

Figures 7(a) through (c) show the misorientation distributions of the accumulative roll bonded samples together with their fraction of high-angle grain boundaries $f_{\mathrm{HAB}}$ and their average misorientation angle $\theta$. The most misoriented microstructure corresponds to the 35DT3 sample. The less misoriented microstructure corresponds to the 40DT3 sample. The 30DT3 sample shows $\theta$ and $f_{\mathrm{HAB}}$ between those of the 35DT3 and 40DT3 samples, although more similar to those of the $35 \mathrm{DT} 3$ one. It is noteworthy that in the three specimens, there is a significant amount of LABs, compared with typically recrystallized microstructures. This is a distinctive feature of the UFG microstructure fabricated by SPD. ${ }^{[19]}$ The 40DT3 sample shows the highest peak in the low-angle area. This sample has practically only LABs. The 35DT3 and 30DT3 samples show much lower peaks in the low-angle region, especially the 35DT3 one, which has a flatter misorientation distribution, while the 30DT3 one has a clear peak in the highangle region at 55 to $60 \mathrm{deg}$.

Orientation data of the three accumulative roll bonded samples are plotted in $\{111\}$ pole figures in Figures 8(a) through (c). A typical $\beta$-fiber rolling

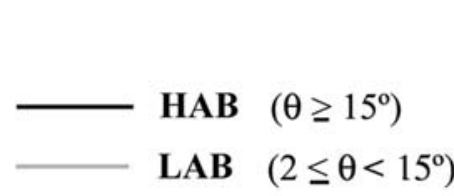

(b)

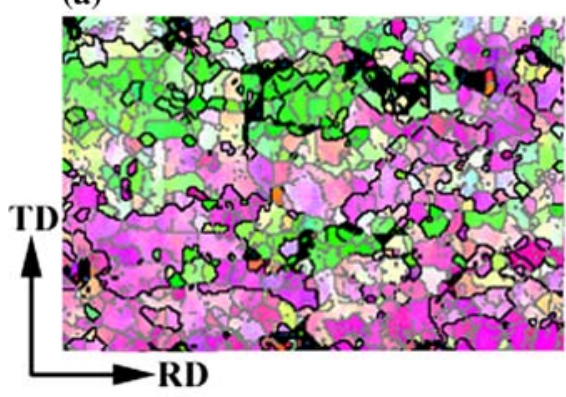

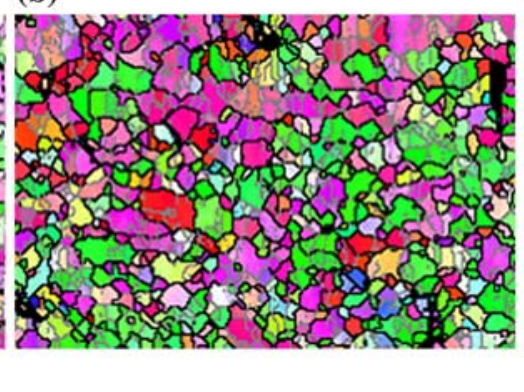

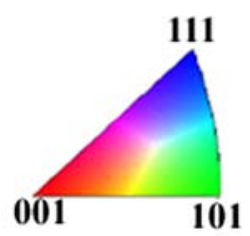

(c)

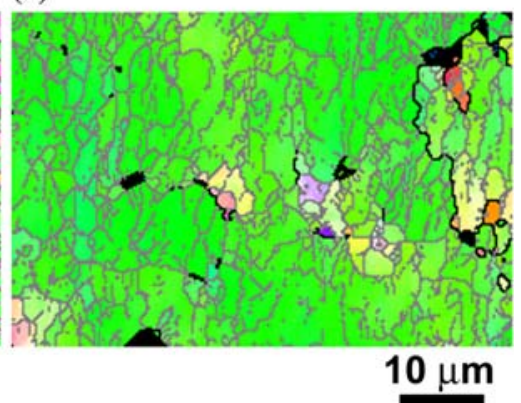

Fig. 6 - Orientation imaging micrographs of the accumulative roll bonded samples obtained by EBSD: (a) 30DT3, (b) 35DT3, and (c) 40DT3. 


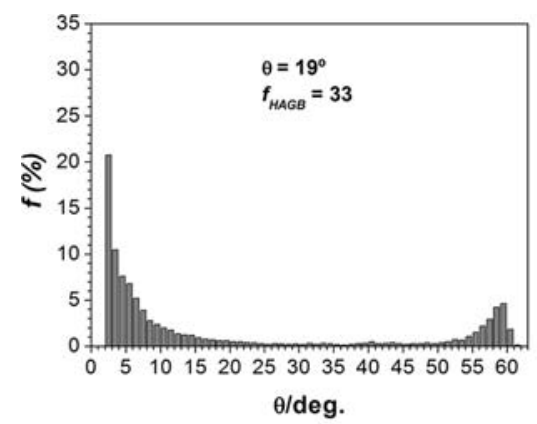

(a)

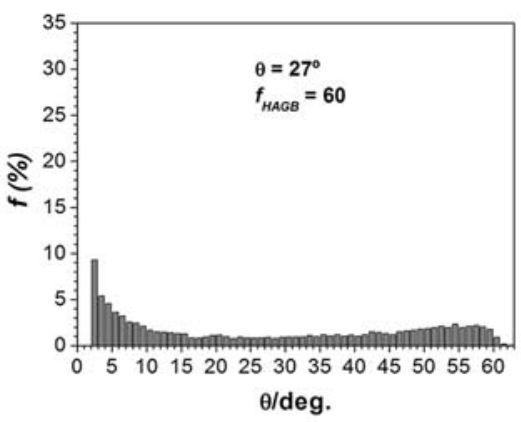

(b)

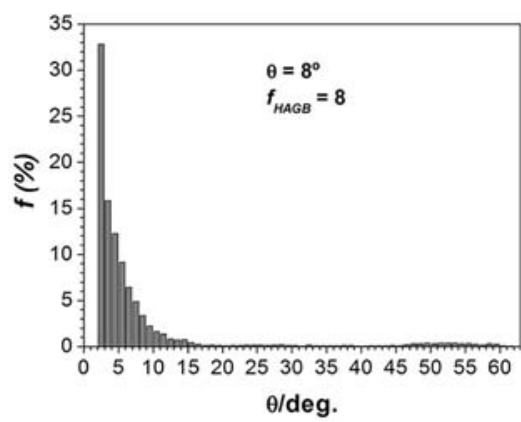

(c)

Fig. 7-Misorientation distributions of the accumulative roll bonded samples obtained from the EBSD data: (a) 30DT3, (b) 35DT3, and (c) 40DT3.

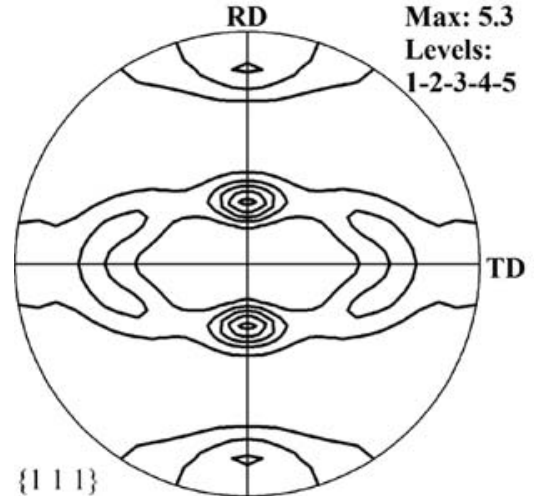

(a)

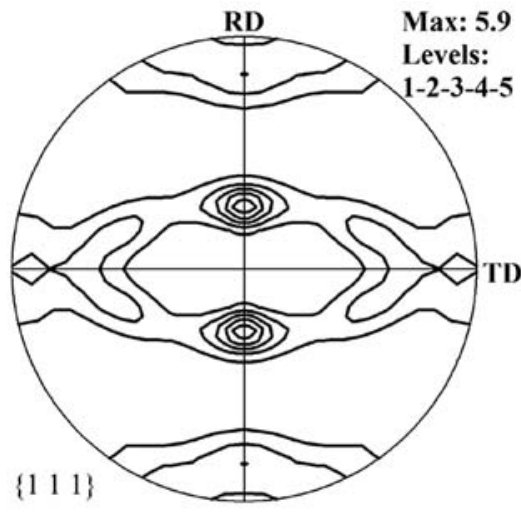

(b)

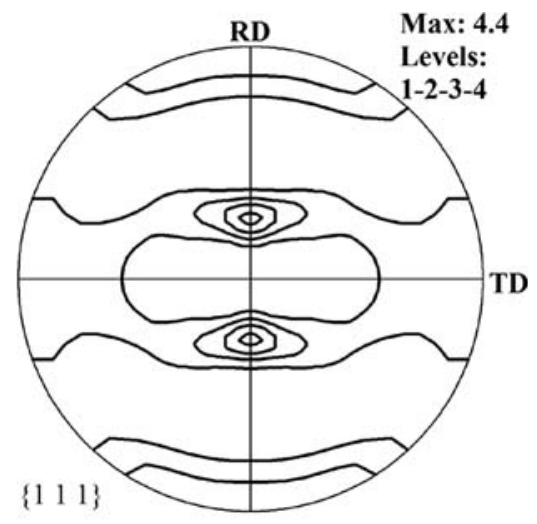

(c)

Fig. $8-\{111\}$ pole figures of the accumulative roll bonded samples: (a) 30DT3, (b) 35DT3, and (c) 40DT3.

texture, comprising variants of ideal components Copper $\{112\}\langle 110\rangle(\mathrm{Cu}), \quad \mathrm{S} \quad\{123\}\langle 634\rangle$, and Brass $\{110\}\langle 112\rangle$ (B), is well developed in the three accumulative roll bonded samples. However, texture intensities are different. The highest value corresponds to the 35DT3 sample, the lowest one to the 40DT3 sample, and the intermediate one, close to the highest one, corresponds to the 30DT3 sample.

A detailed analysis of texture is presented using the ODFs. The complete ODFs are presented in Figures 9(a) through (c). The texture of the accumulative roll bonded samples consists of a strong rolling texture with clear dominance of $\beta$ fiber, especially in the 30DT3 and 35DT3 samples. In these two samples, which show very similar textural features, the major texture components are those comprised between Dillamore $\left\{\begin{array}{lll}4 & 11\end{array}\right\}\left\langle\begin{array}{llll}11 & 11 & 8\rangle\end{array}\right.$ (D), near $\mathrm{Cu}$, and S. Nevertheless, the texture intensity is somewhat higher for the 35DT3 sample, with a $\beta$ fiber displaced toward the D orientation. The 40DT3 sample texture intensity is lower than that of the 30DT3 and 35DT3 samples, and the density along the $\beta$ fiber is more homogeneously distributed.

For a better understanding of the texture, the main fcc fibers are represented in Figures 10(a) through (c). A large spreading around the ideal orientations is observed in the three fibers. The $\alpha$ fiber is presented in Figure 10(a). It shows that for this fiber, texture is mainly centered on the B component in the three accumulative roll bonded samples. Figure 10(b) shows the $\tau$ fiber. The maximum intensity of the $\tau$ fiber in the accumulative roll bonded samples is obtained within the scatter of D orientation, but a small peak at around G orientation is also observed. While in the 30DT3 and 35DT3 samples the D component is prominent, in the 40DT3 one, it is lower and shifts to $\mathrm{Cu}$. In all the accumulative roll bonded samples, there was no signature along this fiber of the $\{001\}\langle 110\rangle$ and $\{111\}\langle u v w\rangle$ components, typical shear texture components in fcc metals. Figure 10(c) represents the $\beta$ fiber. In the 30DT3 and 35DT3 samples, the overall intensity along the D to $\mathrm{S}$ position is higher than along the $\mathrm{S}$ and $\mathrm{B}$ positions. However, in the 30DT3 sample, S and D components show similar intensity, while in the 35DT3 one, the highest intensity is located at the D position. The 40DT3 sample shows a nearly homogeneous $\beta$ fiber.

Figure 11 shows the values of Vickers hardness through the thickness of the accumulative roll bonded samples. The hardness of the specimens is about constant through thickness. The average Vickers hardness values of the as-received material and the accumulative roll bonded samples are listed in Table IV. The hardness of the starting material (182) is higher than those of the deformed samples (100 to 126). The highest hardness in the ARB processed samples belongs to the 
(a)

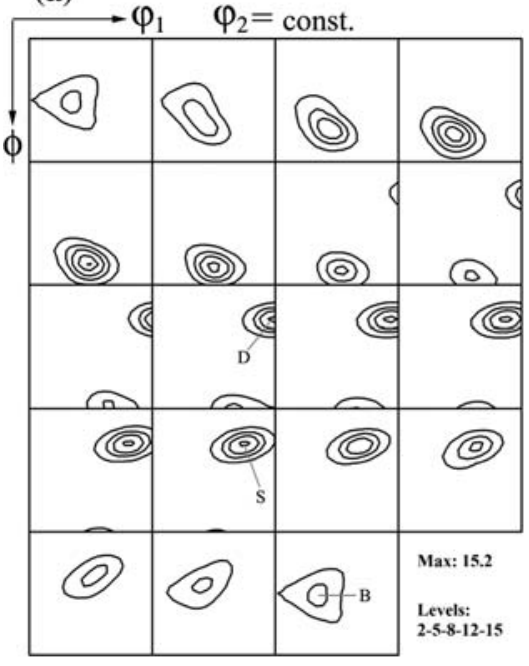

(b)

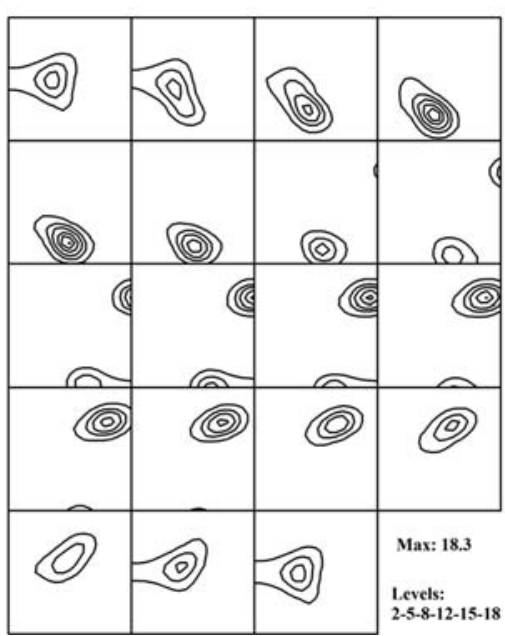

(c)

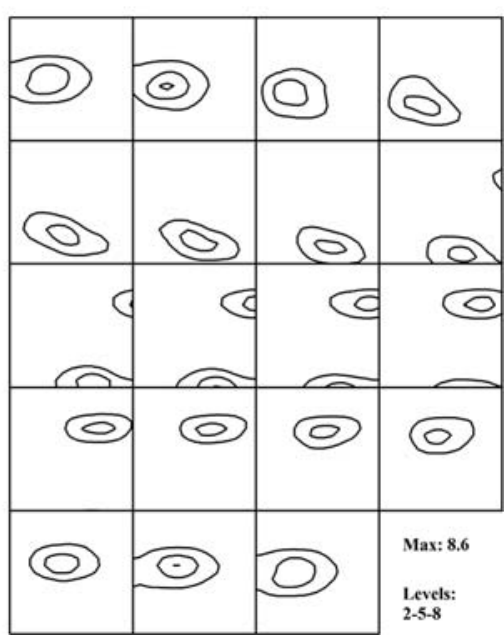

Fig. 9-ODFs of the accumulative roll bonded samples: (a) 30DT3, (b) 35DT3, and (c) $40 \mathrm{DT} 3$.

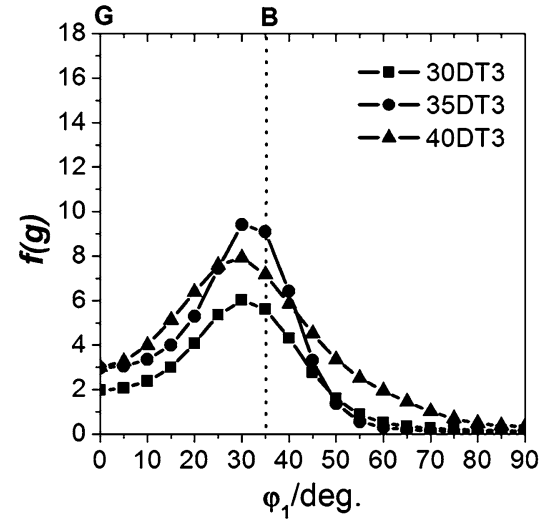

(a)

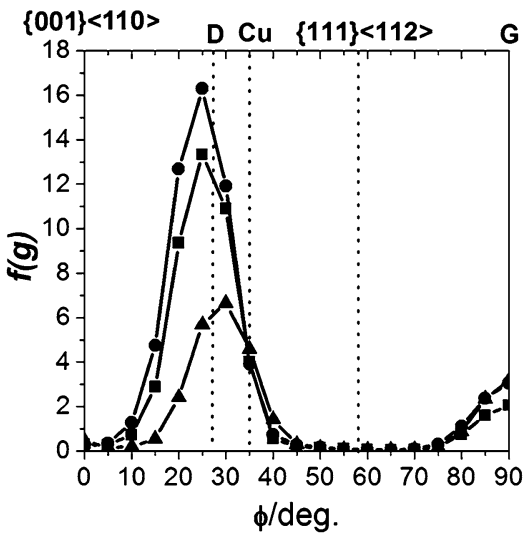

(b)

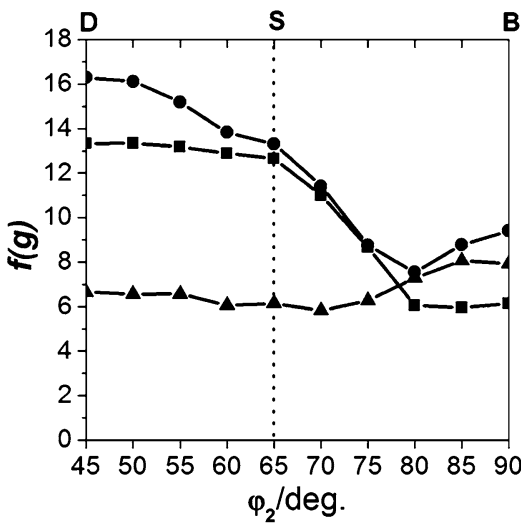

(c)

Fig. 10 - Intensity of the fcc fibers in the accumulative roll bonded samples: $(a) \alpha$ fiber, $(b) \tau$ fiber, and (c) $\beta$ fiber.

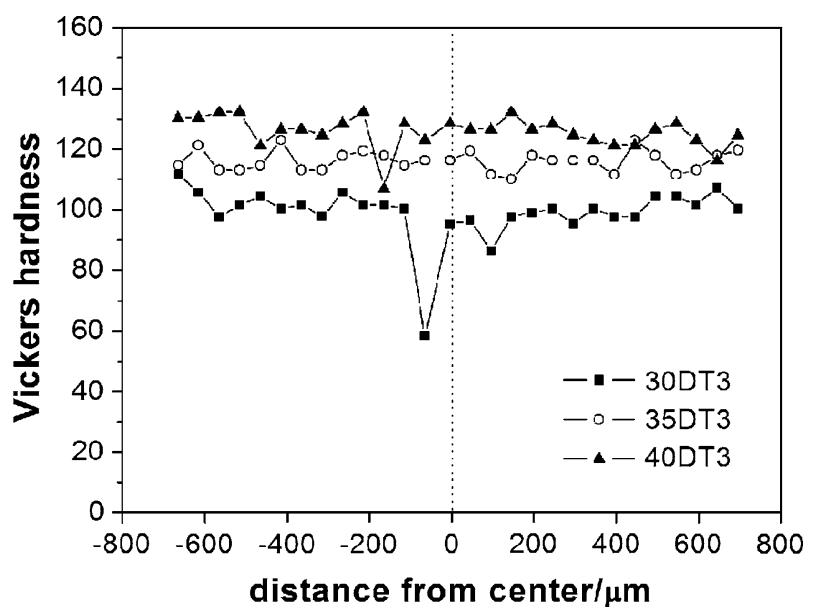

Fig. 11-Through-thickness hardness profiles of the accumulative roll bonded samples.

40DT3 sample and the smallest to the 30DT3 one; i.e., unexpectedly, the hardness increases with an increase in the processing temperature.
Table IV. Vickers Hardness of the As-Received Material and the Accumulative Roll Bonded Samples

\begin{tabular}{lc}
\hline Sample & Vickers Hardness \\
\hline As-received & $182 \pm 5$ \\
30DT3 & $100 \pm 5$ \\
35DT3 & $116 \pm 3$ \\
40DT3 & $126 \pm 4$ \\
\hline
\end{tabular}

\section{DISCUSSION}

\section{A. Microstructure}

Dynamic recovery (DRV) occurs readily during hot working of metals of high stacking fault energy such as aluminum. The flow stress rises during the initial stage of deformation as dislocations multiply and interact. However, the rate of DRV also increases as the dislocation density increases and dislocations begin to rearrange and form LABs as subgrains develop. Eventually, the flow stress saturates as hardening (due to dislocation multiplication) and DRV (due to dislocation rearrangement) 
reach a dynamic equilibrium. This leads to a steady state wherein the flow stress remains constant with strain. The ideal steady state is characterized by equiaxed subgrains with nearly dislocation-free interiors, homogeneous subgrain size, and increasing boundary misorientation with strain. The degree of fulfilment of all these microstructural characteristics, which generally increases with temperature, assesses the degree of DRV, which has a relevant role on the evolution of the Al alloy microstructure during deformation. In addition, according to the theoretical approaches of restoration processes, the subgrain size increases with the processing temperature during DRV. ${ }^{[20]}$

However, the TEM observations and the EBSD data, including dislocation density, $f_{\mathrm{HAB}}, \theta$, and the relative heights of the peaks of the misorientation distributions show that the degree of DRV follows the order $35 \mathrm{DT} 3>30 \mathrm{DT} 3>40 \mathrm{DT} 3$. This is congruent with the better quality of the rolled 35DT3 sample, compared with that of the 30DT3 and 40DT3 samples. Moreover, measurements of the boundary spacing from TEM micrographs show that the relative (sub)grain size of the accumulative roll bonded samples surprisingly does not correspond with their relative processing temperature, since all of them are very similar $(\sim 450 \mathrm{~nm})$.

The commercial $7075 \mathrm{Al}$ alloy used for this work was supplied with the T6-type temper, in which the alloy has the optimum combination of strength, ductility, and toughness. The hardening precipitates completely dissolve at $465^{\circ} \mathrm{C}$. However, the onset of dissolution normally occurs at lower temperatures. The presence of elements in solid solution hinders dislocation motion in the matrix, ${ }^{[21]}$ so limiting the degree of DRV. At the same time, the dissolution and coarsening of the precipitates suppresses their pinning effect on the (sub)structure. These two aspects favor the attainment of a poorly misoriented microstructure. The results suggest that at $400{ }^{\circ} \mathrm{C}$ both factors could affect the final microstructure. Furthermore, the increasing amount of solid solution in the matrix could affect the corresponding processing strength for each temperature, resulting in very similar grain sizes.

It is well established that a decrease in grain size enhances the optimum superplastic response by increasing the strain rate and lowering the temperature for optimum superplasticity. ${ }^{[22]}$ In this sense, the resultant microstructures in the three accumulative roll bonded samples, in the nanostructure range, represent the ideal conditions for superplasticity. Moreover, high misorientation favors grain boundary sliding (GBS), the mechanism which takes place during superplasticity flow. Additionally, the small grains should be stable at the high temperatures at which the superplastic flow occurs. The 35DT3 sample has the maximum misorientation and the minimum dislocation density. Therefore, the best thermal stability and the best superplastic properties are expected for the 35DT3 sample.

\section{B. Texture}

In the absence of discontinuous recrystallization, plane strain deformation of fcc metals, such as that encountered in the rolling process, causes orientations to concentrate along the $\alpha$ and $\beta$ fibers. ${ }^{[23,24]}$ It is generally observed that at low strains, orientations develop uniformly along both fibers. With increasing deformation, the intensity along the fibers becomes nonuniform. For aluminum, the intensity along the $\alpha$ fiber disappears except near the B location and $\mathrm{B}, \mathrm{S}$, and $\mathrm{Cu}$ components increase. The relative intensities of the different texture components along the $\beta$ fiber strongly depend on the strain applied to the material. At intermediate degrees of rolling, a homogeneous $\beta$ fiber is observed and at high degrees of rolling the $\beta$ fiber deteriorates by developing higher intensities between $\mathrm{S}$ and $\mathrm{Cu}$-type positions, particularly at $\mathrm{Cu}$-type positions. ${ }^{[25]}$ The microstructure in the 40DT3 sample is equivalent to that which would be reached at an intermediate degree of rolling. This is congruent with a homogeneous $\beta$ fiber. However, the 30DT3 and 35DT3 samples have a microstructure equivalent to that which would be reached at a high degree of rolling. This explains the presence of a $\beta$ fiber more displaced toward the $D$ position, especially in the 35DT3 sample. In addition, the intensity of rolling texture normally increases with the degree of rolling. ${ }^{23]}$ So, according to the correlations established previously, the relative intensities observed in the three accumulative roll bonded samples (35DT3 > 30DT3 > 40DT3) are coherent.

Taking into account that the texture analysis was made near the center of thickness, the absence of shear orientations and the symmetry of the pole figures show that shear texture components that were introduced into the sheet surfaces during the previous rolling pass were totally destroyed in the last rolling pass, when they were located in the center. ${ }^{[13,14]}$

According to the EBSD maps of the accumulative roll bonded samples, each of the different rolling texture components tend to concentrate in different regions, usually separated by HABs. However, these differently oriented regions are the smallest in size for the 35DT3 sample and the largest for the 40DT3 one, in such a way that, in the map of the latter accumulative roll bonded sample, only one texture component is seen. This is congruent with the relative values of misorientation for the accumulative roll bonded samples $(35 \mathrm{DT} 3>$ 30DT3 > 40DT3). Additionally, the homogeneous distribution of texture components in the 35DT3 sample is consistent with its flat misorientation distribution. In the 30DT3 sample, the more heterogeneous distribution of the predominant rolling texture components gives rise to a remarkable peak at 55 to $60 \mathrm{deg}$. Finally, in the 40DT3 sample, most of the (sub)grains in the map are aligned toward one preferred orientation, which results in a very low misorientation, also reflected in the histogram.

\section{Hardness}

Hardness is a property that is related to the material resistance against plastic deformation. Consequently, all the factors that have an influence on the dislocation mobility may affect the aluminum alloys hardness. In the case of the age-hardenable aluminum alloys, the most relevant factors are interparticle spacing and amount of solid solution, in such a way that hardness 
decreases with increasing interparticle spacing and increases with increasing solid solution.

The hardness of the starting material is the highest because the $7075 \mathrm{Al}$ alloy was supplied with the T6-type temper. The hardness of the accumulative roll bonded samples is lower than that of the starting material due to the increment in the interparticle spacing experienced as a consequence of precipitate coarsening during processing. The interparticle spacing increases with the processing temperature, which cannot explain the relative values of the hardness in the three accumulative roll bonded samples. The amount of elements in solid solution also increases with increasing processing temperature, which is consistent with the increment in hardness with the processing temperature. Therefore, the relative values of the hardness in the three accumulative roll bonded samples are attributed to the relative amount of solid solution. Furthermore, elements in solid solution may reprecipitate partially after processing. This phenomenon of natural aging results in a homogeneous distribution of very fine precipitates, being more closely spaced than the coarse ones, especially for increasing the amount of solid solution. This is also consistent with the increment in hardness with increasing processing temperature. Therefore, fine precipitates produced by reprecipitation of the elements in solid solution may also be responsible for the relative values of the hardness in the ARB processed samples.

\section{CONCLUSIONS}

The 7075 aluminum alloy was severely deformed by a 3:1 reduction per pass $A R B$ process at three temperatures $\left(300{ }^{\circ} \mathrm{C}, 350{ }^{\circ} \mathrm{C}\right.$, and $\left.400{ }^{\circ} \mathrm{C}\right)$ up to an approximately true strain of 3.3 . The microstructure, texture, and hardness of the severely ARB processed material were studied. The results obtained can be summarized as follows.

1. Cell/(sub)grain sizes in the nanostructured range $(\sim 450 \mathrm{~nm})$ are obtained.

2. At $400{ }^{\circ} \mathrm{C}$, the presence of elements in solid solution and the partial dissolution of the hardening precipitates lead to a poorly misoriented microstructure with a high dislocation density. Texture is characterized by a homogeneous $\beta$-fiber rolling texture, which is typical of intermediate degrees of rolling.

3. At $350{ }^{\circ} \mathrm{C}$ and $300{ }^{\circ} \mathrm{C}$, much more misoriented microstructures with lower dislocation density are observed, especially at $350{ }^{\circ} \mathrm{C}$, wherein the degree of DRV is higher. Texture consists in heterogeneous $\beta$-fiber rolling texture with intensities displaced toward S and Dillamore positions at $300{ }^{\circ} \mathrm{C}$ and toward Dillamore position at $350{ }^{\circ} \mathrm{C}$, which are typical of high degrees of rolling.

4. Regarding the microstructure, the optimum processing temperature up to a true strain of 3.3 is $350{ }^{\circ} \mathrm{C}$ since it produces the highest misorientation. The best superplastic properties are expected for those samples processed at these experimental conditions.
5. Hardness of the accumulative roll bonded samples, which is homogeneous through thickness, is smaller than that of the starting material due to the particle coarsening experienced during the ARB process. It is affected by solid solution and/or fine precipitates produced by reprecipitation of the elements in solid solution.

\section{ACKNOWLEDGMENTS}

Financial support from CICYT (Project Nos. MAT2003-01172 and MAT2006-11202) is gratefully acknowledged. Two of the authors, $\mathrm{PH}$ and $\mathrm{CMC}$, thank CSIC for an I3P fellowship and an I3P contract, respectively. We also thank A. García-Delgado for assistance with electron microscopy and C.C. Moreno-Hernández and J.A. Jiménez- Rodríguez for assistance with X-ray diffraction. Finally, the authors make a special mention in memory of P.J. González-Aparicio for his assistance with electron microscopy during all these years.

\section{REFERENCES}

1. Y.S. Chen, Q.D. Wang, H.J. Roven, M. Karlsen, Y.D. Yu, M.P. Liu, and J. Hjelen: J. Alloy Compd., 2008, vol. 462, pp. $192-200$.

2. J.M. García-Infanta, A.P. Zhilyaev, A. Sharafutdinov, O.A. Ruano, and F. Carreño: J. Alloy Compd., 2009, vol. 473, pp. 163-66.

3. Y. Saito, H. Utsunomiya, N. Tsuji, and T. Sakai: Acta Mater., 1999, vol. 47, pp. 579-83.

4. H.W. Kim, S.B. Kang, N. Tsuji, and Y. Minamino: Metall. Mater. Trans. A, 2005, vol. 36A, pp. 3151-63.

5. W.Q. Cao, A. Godfrey, N. Hansen, and Q. Liu: Metall. Mater. Trans. A, 2009, vol. 40A, pp. 204-14.

6. M. Shaarbaf and M.R. Toroghinejad: Metall. Mater. Trans. A, 2009, vol. 40A, pp. 1693-700.

7. N. Tsuji, Y. Saito, S.-H. Lee, and Y. Minamino: Adv. Eng. Mater., 2003, vol. 5, pp. 338-44.

8. S.H. Lee, Y. Saito, N. Tsuji, H. Utsunomiya, and T. Sakai: Scripta Mater., 2002, vol. 46, pp. 281-85.

9. N. Kamikawa, T. Sakai, and N. Tsuji: Acta Mater., 2007, vol. 55, pp. 5873-88.

10. S.-H. Lee, H. Inagaki, H. Utsunomiya, Y. Saito, and T. Sakai: Mater. Trans., 2003, vol. 44, pp. 1376-81.

11. S.-H. Lee, H. Utsunomiya, and T. Sakai: Mater. Trans., 2004, vol. 45, pp. 2177-81.

12. P.B. Prangnell, J.R. Bowen, and P.J. Apps: Mater. Sci. Eng. A, 2004, vols. 375-377, pp. 178-85.

13. S.G. Chowdhury, V.C. Srivastava, B. Ravikumar, and S. Soren: Scripta Mater., 2006, vol. 54, pp. 1691-96.

14. S.G. Chowdhury, A. Dutta, B. Ravikumar, and A. Kumar: Mater. Sci. Eng. A, 2006, vol. 428, pp. 351-57.

15. E.A. Starke, Jr and J.T. Staley: Prog. Aerospace Sci., 1996, vol. 32, pp. 131-72.

16. R. DeIasi and P. Adler: Metall. Trans. A, 1977, vol. 8A, pp. 117783.

17. S.H. Lee, Y. Saito, T. Sakai, and H. Utsunomiya: Mater. Sci. Eng. $A$, 2002, vol. 235, pp. 228-35.

18. C.M. Cepeda-Jiménez, M. Pozuelo, O.A. Ruano, and F. Carreño: J. Alloy Compd., 2009, vol. 478, pp. 154-62.

19. B.L. Li, N. Tsuji, and N. Kamikawa: Mater. Sci. Eng. A, 2006, vol. 423 , pp. $331-42$.

20. F.J. Humphreys and M. Hatherly: in Recrystallization and Related Annealing Phenomena, Elsevier, Oxford, United Kingdom, 2004.

21. M.Z. Quadir, O. Al-Buhamad, L. Bassman, and M. Ferry: Acta Mater., 2007, vol. 55, pp. 5438-48.

22. O. Ruano and O. Sherby: Rev. Met. CENIM, 1983, vol. 19, pp. 261-70. 
23. J. Hirsch and K. Lücke: Acta Metall., 1988, vol. 36, pp. 2863-82.

24. R.D. Doherty, D.A. Hughes, F.J. Humphreys, J.J. Jonas, D. Juul Jensen, M.E. Kassner, W.E. King, T.R. McNelley, H.J. McQueen, and A.D. Rollett: Mater. Sci. Eng. A, 1997, vol. 238, pp. 219-74. 25. W. Mao: Mater. Sci. Eng. A, 1998, vol. 257, pp. 171-77.
26. C.P. Heason and P.B. Prangnell: Proc. 2nd Int. Conf. on Nanomaterials by Severe Plastic Deformation (NANOSPD2), Institute of Materials Physics of the University of Vienna, Vienna, Austria, 2002, pp. 498-504. 